Tropical Journal of Pharmaceutical Research June 2016; 15 (6): 1321-1325

ISSN: $1596-5996$ (print); 1596-9827 (electronic) (C) Pharmacotherapy Group, Faculty of Pharmacy, University of Benin, Benin City, 300001 Nigeria. All rights reserved.

\title{
Complications associated with malnutrition in elective surgical patients in a Malaysian setting
}

\author{
Nur S Mohd Abdul Latiff ${ }^{1}$, Nurulumi Ahmad ${ }^{2}$ and Farida Islahudin ${ }^{2 *}$ \\ ${ }^{1}$ Pharmacy Department, Hospital Tanjung Karang, Tanjung Karang, 45500 Selangor, ${ }^{2}$ Faculty of Pharmacy, Universiti \\ Kebangsaan Malaysia, Jalan Raja Muda Abdul Aziz, 50300 Kuala Lumpur, Malaysia
}

*For correspondence: Email: faridaislahudin@yahoo.com; Tel: 00603-92897689

Received: 4 February 2015

Revised accepted: 13 April 2016

\begin{abstract}
Purpose: To identify the level of malnutrition and complications observed in Malaysia. Methods: A prospective, observational study was conducted with the objectives of identifying the degree of malnutrition, complications and the need for nutritional support in elective surgical patients. Collection of data was performed in local tertiary hospitals using a Patient Generated Subjective Global Assessment (PG - SGA) nutritional screening tool and medical records.

Results: A total of 50 patients electively admitted for surgery were included. The results demonstrated that there was a significant increase in malnourished patients post-surgery compared to pre-surgery ( $p$ $=0.0001)$. Most interesting was the significant number of complications observed post-surgery compared to pre-surgery $(p=0.035)$ which was associated to the poor level of nutrition. The most common type of complications noted post-surgery were nosocomial infection, wound infection and readmission.

Conclusion: Malnutrition is prevalent pre- and post-operatively in Malaysia. Therefore, focus on the outcome of these malnourished patients should be performed to reduce complications associated with poor nutrition.
\end{abstract}

Keywords: Malnutrition, Nutrition, Surgery, Complications

\begin{abstract}
Tropical Journal of Pharmaceutical Research is indexed by Science Citation Index (SciSearch), Scopus, International Pharmaceutical Abstract, Chemical Abstracts, Embase, Index Copernicus, EBSCO, African Index Medicus, JournalSeek, Journal Citation Reports/Science Edition, Directory of Open Access Journals (DOAJ), African Journal Online, Bioline International, Open-J-Gate and Pharmacy Abstracts
\end{abstract}

\section{INTRODUCTION}

Hospital malnutrition contributes to high morbidity and mortality rates [1]. Nutritional risk is strongly associated with increased post-operative morbidity and mortality following elective surgery [2]. Despite this, malnutrition is still prevalent with approximately $30-40 \%$ of admitted patients showing some degree of malnutrition [3]. In surgery patients, approximately $40 \%$ are malnourished $[4,5]$. In view of this, the provision of nutritional care is essential in hospitalised patients and involves responsibility towards patient care to promote maintenance and/or restoration of optimal nutritional status according to the needs of the patient [3].

Malnutrition may affect all three phases; inflammation, proliferative, and re-modelling of the wound-healing process due to vitamin and mineral deficiencies [4]. Patients with malnutrition are at a higher risk for infection, organ failure, decreased wound healing, and suboptimal response to regular medical treatment [6-9]. A higher number of complications and a longer hospital stay have been demonstrated amongst malnourished patients $[6,7,10]$. Despite reports of complications in malnourished patients going for surgery, there is a lack of data supporting this in 
the local population. Therefore, this work is performed to identify the level of malnutrition and its effects in elective surgical patients in Malaysia.

\section{EXPERIMENTAL}

\section{Study design and setting}

This study was a prospective observational study performed in Hospital Putrajaya under the Ministry of Health in Malaysia. Patients included in the study were elective surgical patients aged 18 and above with informed consent. Patients were excluded if they were admitted for stroke or comatose and critically ill patients who were not available or unable to be interviewed. Patient medical records were also screened for data. Ethical approval was obtained from the local medical research and ethics committee (ID: NMRR-10-373-5659).

\section{Data collection}

The type of surgery was recorded for each patient based on minor or major surgery as noted in the medical records by clinicians. The local practice defines minor surgery as intervention on superficial areas, incision or excision on lesion of skin that neither penetrates nor exposes a body cavity, and that may require regional or general anesthesia [10]. Major surgery was defined as any intervention occurring involving the incision or excision with manipulation, or suturing of tissue, and that requires regional or general anesthesia or profound sedation to control pain [10]. The nutritional status of patients was assessed using a scored Patient Generated
Subjective Global Assessment (PG-SGA) form [11]. It comprises of four medical components; weight loss, condition, metabolic stress and physical examination. For each component, points are awarded depending on the impact of the symptom on nutritional status. The PG-SGA then provides a global rating scale of three nutrition levels; SGA A: nourished, SGA B: moderately or suspected of being malnourished, or SGA C: severely malnourished.

\section{Data analyses}

Analyses were performed using the statistical package SPSS version 21.0. Descriptive statistics such as mean and standard deviation was used to analyse the continuous and categorical data. Chi - square test or Fishers exact test was used to make a comparison and association between the SGA scores, complications and length of stay pre and postsurgery. A value of $p<0.05$ was considered significant.

\section{RESULTS}

\section{Patient demographics}

During the 8 months study duration only 50 patients agreed to be included in the study. Patients ranged from 22 to 79 years old with a mean age of $50.4( \pm 13.88)$ years. The mean height of patients was $1.58( \pm 0.097)$ metres. Initial weight of the patients was an average of $67.64( \pm 15.73) \mathrm{kg}$ (Table 1). There were a total of $3(6 \%)$ patients categorized under minor surgery and 47 (94\%) patients as major surgery.

Table 1: Demographic data for surgery patients included during the study $(N=50)$

\begin{tabular}{lc}
\hline Characteristic & $\mathbf{N}(\%)$ \\
\hline $\begin{array}{l}\text { Gender } \\
\text { Male }\end{array}$ & $11(22)$ \\
Female & $39(78)$ \\
Type of surgery & $16(32)$ \\
Breast & \\
$\quad$ Simple mastectomy & \\
$\quad$ Simple mastectomy with axillary clearance & \\
Quadrantectomy with axillary clearance & \\
Endocrine & $25(50)$ \\
$\quad$ Thyroidectomy & \\
$\quad$ Parathyroidectomy & \\
GIT $\quad$ Colectomy & $7(14)$ \\
$\quad$ Laparascopic cholecystectomy & \\
$\quad$ Reversal of Hartman's procedure & \\
Hernioplasty & $2(4)$ \\
Others & \\
Implant removal & \\
$\quad$ Breast reduction and nipple reposition &
\end{tabular}




\section{Nutrition status}

The mean weight of post-surgery, 66.96 ( \pm 15.73) kg, was significantly lower than presurgery weight, $67.64( \pm 15.73) \mathrm{kg}(p=0.0001$, $95 \%$ Confidence interval $(\mathrm{Cl}):-0.95,-0.41)$. A total of $10 \%(N=5)$ lost weight, $46 \%(N=23)$ remained the same, and $44 \%(N=22)$ gained weight. Prior to surgery, the patient's nutritional status were assessed with a majority $(N=34,68$ $\%)$ of the patients classified as either SGA A (well-nourished) or SGA B (suspected/moderate malnutrition) ( $\mathrm{N}=16,32 \%$, Table 2). However, during post-surgery, overall there were significant changes; SGA A decreased to $8 \%(N=4)$, SGA $B$ and SGA C increased to $58 \%(N=29)$ and 34 $\%(\mathrm{~N}=17)$ respectively $(p=0.0001)$. When analysed by type of surgery, there was a significant change of nutritional status under major surgery $(\mathrm{N}=47$ patients): SGA $\mathrm{A}$ decreased to $2 \%(n=1)$ from $66 \%(N=31)$, SGA $B$ and SGA $C$ increased to $62 \%(N=29)$ from $34 \%(N=16)$ and $36 \%(N=17)$ from $0 \%$ $(\mathrm{N}=0)$ respectively $(p=0.0001)$. No changes were observed under minor surgery (SGA A = 3 patients). It was demonstrated that factors that affected overall nutritional status post-surgery were 'no appetite' $(p=0.0001)$ and 'nausea/vomiting' ( $p=0.048)$.

\section{Complications and length of stay}

A total of $12 \%(\mathrm{~N}=6)$ of the patients in the study population developed complications postsurgery; $4 \%(\mathrm{~N}=2)$ nosocomial pneumonia, $6 \%$ $(\mathrm{N}=3)$ wound infection and $2 \%(\mathrm{~N}=1)$ readmission. All complications were noted to occur in patients undergoing major surgery. These patients were well-nourished prior to surgery (SGA A) and no complications were noted in these patients prior to surgery. However, their nutritional status changed after surgery to $10 \%$ ( $\mathrm{N}=5)$ SGA $\mathrm{B}$ suspected (or moderate) malnutrition and $2 \%(\mathrm{~N}=1)$ SGA $\mathrm{C}$ severe malnutrition. When analysed for major elective surgery patients only, there was an increase in the number of complications post-surgery in these malnourished patients $(p<0.0001)$. Similarly, there was a significant overall increase in the number of complications observed postsurgery in these patients $(p=0.035)$ (Table 3$)$.

\section{DISCUSSION}

The aim of the study is to seek how the degree of malnutrition amongst elective surgical patients in the local population was achieved. Malnutrition is associated with poor clinical outcomes; however, patients going for elective surgery are rarely assessed in the clinical setting. Although there is no single marker which is consistent with nutritional assessment for the critically ill, there are several indicators used in identifying malnutrition in patients [11]. Indeed it was noted that the mean age of patients was similar to recent work involving elective surgical patients [12]. Similarly, on admission the number of malnourished patients was approximately $32 \%$ which is also similar to previous findings $[13,14]$. The state of malnutrition prior to surgery should be given special attention as their disease status could worsen nutrition state post-surgery. Prior to surgery, malnutrition may be present due to various reasons in patients undergoing elective surgery. This includes metabolic disorders from inflammatory or neoplastic disease, altered nutrient utilization due to metabolic state, poor access to adequate nutrition, or alimentary track dysfunction $[14,15]$.

Table 2: SGA categories of patients pre- and post-surgery $(N=50)$

\begin{tabular}{|c|c|c|c|c|c|}
\hline \multirow[t]{2}{*}{ Variable } & \multicolumn{3}{|c|}{ SGA } & \multirow[t]{2}{*}{ Total } & \multirow[t]{2}{*}{$P$ value } \\
\hline & $A$ & $B$ & $C$ & & \\
\hline $\begin{array}{l}\text { SGA pre-surgery, n (\%) } \\
\text { SGA post-surgery, n (\%) }\end{array}$ & $\begin{array}{r}34(68.0) \\
4(8.0)\end{array}$ & $\begin{array}{l}16(32.0) \\
29(58.0)\end{array}$ & $\begin{array}{r}0(0.0) \\
17(34.0)\end{array}$ & $\begin{array}{l}50(100.0) \\
50(100.0)\end{array}$ & $\begin{array}{l}0.0001^{*} \\
0.0001^{*}\end{array}$ \\
\hline
\end{tabular}

Significant when $p<0.05$; Chi-square test/Fishers-exact test

Table 3: SGA categories and complications of overall patients pre- and post-surgery $(n=50)$

\begin{tabular}{|c|c|c|c|c|c|c|c|}
\hline \multirow[t]{2}{*}{ Variable } & \multicolumn{3}{|c|}{ SGA pre-surgery, n (\%) } & \multicolumn{3}{|c|}{ SGA post-surgery, n (\%) } & \multirow[t]{2}{*}{$P$-value } \\
\hline & A & B & C & A & B & C & \\
\hline $\begin{array}{l}\text { No complications } \\
\text { Complications }\end{array}$ & $28(56)$ & $16(32)$ & $0(0)$ & $4(8)$ & $24(48)$ & $16(32)$ & $0.035^{\star}$ \\
\hline Pneumonia & $0(0)$ & $0(0)$ & $0(0)$ & $0(0)$ & $1(2)$ & $1(2)$ & \\
\hline Wound infection & $0(0)$ & $0(0)$ & $0(0)$ & $0(0)$ & $3(6)$ & $0(0)$ & \\
\hline Re-admission & $0(0)$ & $0(0)$ & $0(0)$ & $0(0)$ & $1(2)$ & $0(0)$ & \\
\hline
\end{tabular}

* Significant when $p<0.05$; Fishers-exact test 
Despite this, no additional nutrition was given to this group of patients despite their malnutrition state. In general, patients admitted for elective surgery do not require special nutrient requirements [15], although their various disease status [14] itself more often lends to poor nutrient intake that places the patient at risk. Indeed, intervening with oral, enteral, or parenteral preoperative nutrition support is important to optimize the patient's status and achieve the best possible outcome [3]. Although parenteral nutrition does not improve overall mortality rate, it can reduce the rate of complications postsurgery $[14,15]$.

Clearly as observed from the current work, the nutritional status of patients was observed to decline significantly post-surgery. This is especially true for those undergoing major surgery. Moreover, this work demonstrates the importance of screening the nutrition status of patients prior to surgery as a third of the patients were found to be malnourished on admission. It was noted that a dramatic increase from a third of the patients, to $92 \%$ malnourished patients, demonstrates the poor nutrition outcome of patients even in elective surgery.

The slightly higher number of malnourished patients post-surgery compared to previous work $[5,13,14]$, is a factor that should be looked into in the local setting. A contributing factor could be attributed to the high number of malnourished patients that were noted before surgery, as well as the type of surgery [10] the patients underwent. In this current study, the main reasons affecting poor nutritional outcomes amongst this group of patients were most notably loss of appetite and nausea or vomiting. Nutritional intake often decreases during hospitalization due to an increase in pain, nausea, weakness, and altered mood or mental status, repetitive menu cycles as well as dietary restrictions [16].

Complications in malnourished patients have been demonstrated to be a common occurrence [17]. Previous work has shown that the prevalence of nosocomial infections was found to be $4.4 \%$ in non-malnourished, $7.6 \%$ in moderately, and $14.6 \%$ in severely malnourished patients [17]. In patients undergoing major elective surgery, $58.3 \%$ were malnourished and severe infections were significantly higher in this group of patients [18]. This was similarly highlighted in the present work that demonstrated the number of complications were higher in post-surgery malnourished patients.

\section{Limitations of the study}

One major limitation of the study was the number of patients identified during the study period. It is also important to note that the difference in the type of surgery and condition of the patient could affect patient outcomes post-surgery. Although generalization of results should be done cautiously, the significant findings provide an insight of the complications observed in malnourished elective surgery patients in the local setting.

\section{CONCLUSION}

Data on the level of nutrition in elective surgery patients in the local population is comparable to previous findings. Data from this study also provide a basis for a much more stringent approach in nutrition monitoring in elective surgery patients in an attempt to reduce complications associated with malnutrition. As malnutrition is associated with numerous consequences, nutritional support, planning of diet, treatment of nausea and vomiting improving appetite early detection and intervention may prevent its occurrence and improve disease outcomes. Further studies are therefore required for a much larger population to identify factors and other complications associated with malnourishment in elective surgery patients in the local population.

\section{ACKNOWLEDGEMENT}

The authors would like to thank the respondents for their time and effort in participating in this study.

\section{DECLARATIONS}

\section{Conflict of Interest}

No conflict of interest associated with this work.

\section{Contribution of Authors}

The authors declare that this work was done by the authors named in this article and all liabilities pertaining to claims relating to the content of this article will be borne by them.

\section{REFERENCES}

1. Covinsky KE, Martin GE, Beyth RJ, Justice AC, Shegal $A R$, Landefeld CS. The relationship between clinical assessments of nutritional status and adverse outcomes 
in older hospitalized medical patients. J Am Geriatr Soc 1999; 47: 532-538.

2. ASPEN (American Society for Parenteral and Enteral Nutrition). Standards of practice for nutrition support pharmacist. Nutr Clin Pract 2008; 23(2): 189-194.

3. Doerr TD, Marks SC, Shamsa FH, Mathog RH, Prasad AS. Effects of zinc and nutritional status on clinical outcomes in head and neck cancer. Nutr 1998; 14: 399405.

4. Young ME. Malnutrition and wound healing. Heart Lung 1988; 17: 60-67.

5. Corish CA, Kennedy NP. Review article. Protein-energy undernutrition in hospital in-patients. Br J Nutr 2000; 83: 575-591.

6. Kyle UG, Pirlich $M$, Schütz $T$, Lübke HJ, Lochs $H$, Pichard C. Prevalence of malnutrition in 1760 patients at hospital admission: a controlled population study of body composition. Clin Nutr 2003; 22: 473-481.

7. Stratton RJ, Hackston A, Longmore $D$, Dixon R, Price $S$, Stroud M, King C, Elia M. Malnutrition in hospital outpatients and inpatients: prevalence, concurrent validity, and ease of use of the malnutrition universal screening tool (MUST) for adults. Br J Nutr 2004; 92: 799-808.

8. Kondrup J, Allison SP, Elia M, Vellas B, Plauth M. Educational and Clinical Practice Committee, European Society of Parenteral and Enteral Nutrition (ESPEN). ESPEN guidelines for nutrition screening 2002. Clin Nutr 2003; 22: 415-421.

9. Rasmussen $\mathrm{HH}$, Kondrup J, Staun M, Ladefoged $K$, Kristensen $H$, Wengler A. Prevalence of patients at nutritional risk in Danish hospitals. Clin Nutr 2004; 23 : 1009-1015.
10. Weiser TG, Regenbogen SE, Thompson KD, Haynes $A B$, Lipsitz SR, Berry WR, Gawande AA. An estimation of the global volume of surgery: a modelling strategy based on available data. Lancet 2008; 372: 139-144.

11. Ottery FD. Definition of standardized nutritional assessment and interventional pathways in oncology. Nutr 1996; 12: S15-S19.

12. Schwegler I, von Holzen A, Gutzwiller JP, Schlumpf $R$, Mühlebach S, Stanga Z. Nutritional risk in a clinical predictor of postoperative mortality and morbidity in surgery for colorectal cancer. Br J Surg 2010; 97: 92-97.

13. Singh $H$, Watt $K$, Veitch $R$, Cantor $M$, Duerksen $D R$. Malnutrition is prevalent in hospitalized medical patients: Are house staff identifying the malnourished patient? Nutr 2006; 22(4): 350-354.

14. Grover A, Khashu M, Mukherjee A, Kairamkonda V. latrogenic malnutrition in neonatal intensive care units: Urgent need to modify practice. J Parenter Enteral Nutr 2008; 32(2): 140-144.

15. Schlenker ED, Long S. William's essentials of nutrition \& diet therapy. Ninth edition. Missouri: Mosby Elsevier. 2007.

16. Fessler TA. Malnutrition: A serious concern for hospitalized patients. Today's Dietitian 2008; 10(7): 44.

17. Schneider SM, Veyres $P$, Pivot $X$, Soummer AM, Jambou $P$, Filippi J, van Obberghen $E$, Hébuterne $X$. Malnutrition is an independent factor associated with nosocomial infections. Br J Nutr 2004; 92: 105-111.

18. Kuzu MA, Terzioglu H, Genc V, Erkek AB, Ozban M, Sonyurek $P$, Elhan AH, Torun N. Preoperative nutritional risk assessment in predicting postoperative outcome in patients undergoing major surgery. World J Surg 2006; 30: $378-390$. 